\title{
Application of diuretic power index to evaluate the diuretic activity of medicinal plants or drugs
}

\author{
Felipe Hernández-Luis ${ }^{1}$, Susana Abdala ${ }^{2, *}$, Dora Benjumea ${ }^{3}$, Sandra Dévora ${ }^{2}$ \\ and Domingo Martín-Herrera ${ }^{2}$ \\ ${ }^{1}$ U. D. Química Física, Departamento de Química, Universidad de La Laguna, \\ ${ }^{2}$ Unidad de Farmacología y Farmacognosia, Universidad de La Laguna, 38207 La Laguna, \\ Tenerife, Spain. ${ }^{3}$ Departamento de Farmacia, Universidad de Antioquia, Medellín, Colombia.
}

\begin{abstract}
The present research was conducted to test the usefulness of a new index, defined in a previous work, to determine the diuretic power (DP) of medicinal plants and drugs. Plant materials, extract preparation, animals, drugs and procedures for obtaining samples, and measurement units used have been extensively described in previous works. Urine was collected in a graduated cylinder during the $8 \mathrm{~h}$ period after the administration of plants and drugs. $\mathrm{Na}^{+}$and $\mathrm{K}^{+}$concentrations were measured by flame photometry, and $\mathrm{Cl}^{-}$concentration by direct potentiometry using a selective chloride electrode and a reference electrode. Specific electrical conductivity of thermostated fresh urine was determined with a conventional conductivity meter. The results obtained after oral administration of the methanolic extracts of three plants (Artemisia thuscula (AT), Withania aristata (WA) and Smilax canariensis (SC)) and the Hydrochlorothiazide (HCTZ) used as reference drug can clearly show that the HCTZ produced a $40 \%$ increase in DP, with respect to the control group, and the studied plants show an increase up to $21 \%$, in a dose-dependent manner in all the cases. Finally, when DP values were compared with other common indexes, diuretic index (DI) and saluretic index (IS), the sequence variation
\end{abstract}

*Corresponding author: sabdala@ull.es

Dedicated to Prof. Dr. Victoriano Darias del Castillo on the occasion of his retirement after many years at the University of La Laguna. of the three indexes was the same for HCTZ, WA and SC. In the case of AT, small discrepancies were observed that may be due to experimental errors. Briefly, the new and easy method we propose for estimating the diuretic activity of drugs or plants is able to determine the diuretic effect of a particular drug or plant with respect to a specific control value. Its application requires only two experimental parameters: the volume of urinary excretion and the specific electrical conductivity of the sample.

KEYWORDS: specific electrical conductivity, urinary excretion volume, diuretic activity, methanolic extracts, medicinal plant

\section{INTRODUCTION}

Specific electrical conductivity, density, and osmolality are physicochemical parameters usually employed to estimate the total amount of ions present in samples of biological fluids such as urine. The last two parameters are strongly affected by the presence of other non-electrolytes in the solution (glucose, urea, etc.), and the osmolality in particular is not easy to measure [1].

Measurements of urine-specific electrical conductivity have been widely used since the beginning of the last century in different types of studies $[2,3,4,5$, $6,7,8,9,10,11,12,13]$, many of them related to diuresis, either to estimate variations in ions, total amount of water to be excreted or retained in certain situations (diseases) or upon administering certain drugs or herbs. 
In a previous work [14] we have defined a new index, which we called diuretic power (DP), and checked its usefulness by applying it to the urinary samples obtained from rats after oral administration of the aqueous extracts of three endemic plants of the Canary Islands, and Hydroclorothiazide, a wellknown diuretic drug.

To determine diuretic activity after oral administration of drugs or plant extracts, two parameters are commonly used to compare the results obtained for 'control' (without drug or plant extract administration) with others where drugs have been administered at different concentrations. These parameters are the diuretic index (DI), defined as the ratio between the amounts of urine excreted from treated subjects and the non-treated control urine volume, and the saluretic index with respect to the excreted ion $i$ (ISi), defined as the ratio of ion concentrations in the treated and non-treated control groups. Usually, $i$ stands for $\mathrm{Na}^{+}, \mathrm{K}^{+}$or $\mathrm{Cl}^{-}$.

As an example for this application, we have used in this work the methanolic extracts of the three plants aforementioned [15, 16, 17].

\section{MATERIALS AND METHODS}

Plant materials, extract preparation, animals, drugs, acute toxicity test and procedures for obtaining samples, and measurement units used have been extensively described in previous works [15, 16, 17]. Urine was collected in a graduated cylinder with $\pm 0.1 \mathrm{~mL}$ precision for two hours during the $8 \mathrm{~h}$ after the administration of plant extracts and drugs. $\mathrm{Na}^{+}$and $\mathrm{K}^{+}$concentrations were measured using a Jenway Corp. model PFP7 flame photometer. $\mathrm{Cl}^{-}$concentration was measured potentiometrically with an ISE-Cl (Orion 9417B) and a reference electrode $\mathrm{Ag} / \mathrm{AgCl}$ double union (Orion 90-02) connected to an Ionometer (Orio/901). Specific electrical conductivity of thermostated fresh urine at $25.0 \pm 0.1{ }^{\circ} \mathrm{C}$ was determined with a LF-320 WTF conductivity meter.

Results are expressed as the mean values \pm SEM (standard error of mean). The statistical evaluation was carried out by analysis of variance (ANOVA) followed by Student's $t$-test for multiple comparisons. When comparing with control groups, values of $P$ less than 0.05 were considered significant.

\section{RESULTS AND DISCUSSION}

As we have indicated in our previous work [14], the procedure used for calculating the new index called DP was as follows:

1. We measured the specific electrical conductivity, $\kappa$, of the urine samples under study as accurately as possible.

2. We calculated the concentration of a $\mathrm{NaCl}$ (or $\mathrm{KCl}$ ) aqueous solution that has the same specific electrical conductivity of the urine sample. Thus, we made a polynomial interpolation of the $c-\kappa$ data (Table 1), which was obtained from a wide set of data collected from the literature [1].

3. Once we determined the $\mathrm{NaCl}$ (or $\mathrm{KCl}$ ) concentration, this value was multiplied by the corresponding urinary excretion volume, thus obtaining the total mEq. of electrolyte excreted 'as if all were $\mathrm{NaCl}$ (or $\mathrm{KCl}$ )'.

4. Finally, dividing the under-study sample $\mathrm{NaCl}$ (or $\mathrm{KCl}$ ) mEq. by that of the control sample, we obtained its DP value.

Table 2 shows the experimental values of urinary excretion volume and specific electrical conductivity measured for the control group (without any administration), as well as for a widely used reference drug Hydrochlorothiazide (HCTZ) and for the methanolic extracts of three plants studied, Artemisia thuscula (AT), Withania aristata (WA) and Smilax canariensis (SC), after oral administration of the methanolic extracts at different concentrations. It also shows the $\mathrm{NaCl}$ (or $\mathrm{KCl}$ ) aqueous concentration

Table 1. Polynomial fit parameters for the variation $c-\kappa$. $c_{\mathrm{x}}=a+b \kappa+c \kappa^{2}+d \kappa^{3}+e \kappa^{4}+f \kappa^{5}+g \kappa^{6}+h \kappa^{7}+i \kappa^{8}$.

\begin{tabular}{|c|c|c|}
\hline & $\mathrm{X}: \mathrm{NaCl}$ & $\mathrm{X}: \mathrm{KCl}$ \\
\hline$a$ & $-1.8435 \times 10^{-6}$ & $-7.0475 \times 10^{-6}$ \\
\hline$b$ & $8.5309 \times 10^{-3}$ & $7.1925 \times 10^{-3}$ \\
\hline$c$ & $9.5089 \times 10^{-5}$ & $5.1474 \times 10^{-5}$ \\
\hline$d$ & $-2.0768 \times 10^{-6}$ & $-8.9095 \times 10^{-7}$ \\
\hline$e$ & $3.3341 \times 10^{-8}$ & $9.6544 \times 10^{-9}$ \\
\hline$f$ & $-3.1156 \times 10^{-10}$ & $-5.9261 \times 10^{-11}$ \\
\hline$g$ & $1.6806 \times 10^{-12}$ & $2.0300 \times 10^{-13}$ \\
\hline$h$ & $-4.8140 \times 10^{-15}$ & $-3.6060 \times 10^{-16}$ \\
\hline$i$ & $5.7040 \times 10^{-18}$ & $2.5861 \times 10^{-19}$ \\
\hline$\sigma\left(c_{\mathrm{x}}\right)$ & 0.0001 & 0.0008 \\
\hline
\end{tabular}




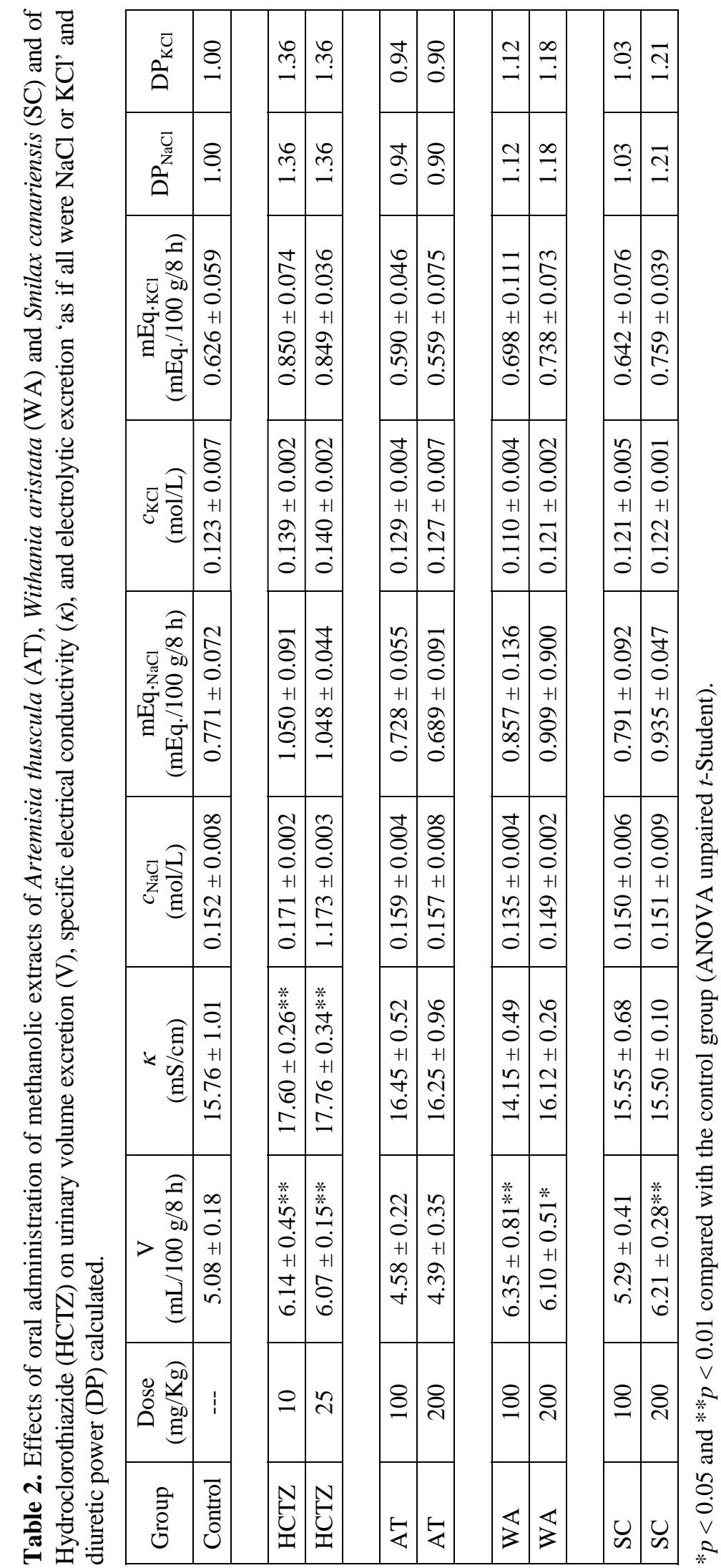


Table 3. Comparison of the different indexes.

\begin{tabular}{|c|c|c|c|c|c|c|c|}
\hline Group & Dose (mg/Kg) & DI & $\mathrm{IS}_{\mathrm{Na}}$ & $\mathrm{IS}_{\mathrm{K}}$ & $\mathrm{IS}_{\mathrm{Cl}}$ & IS* & DP \\
\hline Control & & 1.00 & 1.00 & 1.00 & 1.00 & 1.00 & 1.00 \\
\hline & & & & & & & \\
\hline HCTZ & 10 & 1.21 & 1.32 & 1.53 & 1.29 & 1.38 & 1.36 \\
\hline HCTZ & 25 & 1.21 & 1.30 & 1.42 & 1.42 & 1.38 & 1.36 \\
\hline $\mathrm{AT}$ & 100 & 000 & 101 & 132 & 123 & 120 & 004 \\
\hline $\mathrm{AT}$ & 200 & ס909 & 1.07 & $\frac{1.00}{1.11}$ & $\frac{1.25}{121}$ & $\frac{1.20}{1.14}$ & 1.04 \\
\hline 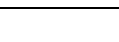 & & & & & & & \\
\hline WA & 100 & 1.25 & 1.21 & 0.96 & 1.48 & 1.22 & 1.05 \\
\hline WA & 200 & 1.26 & 1.23 & 1.32 & 1.23 & 1.26 & 1.15 \\
\hline & & & & & & & \\
\hline SC & 100 & 1.21 & 1.13 & 0.84 & 1.00 & 0.99 & 1.17 \\
\hline SC & 200 & 1.42 & 1.36 & 0.95 & 1.17 & 1.16 & 1.32 \\
\hline
\end{tabular}

$* \mathrm{IS}=\left(\mathrm{IS}_{\mathrm{Na}}+\mathrm{IS}_{\mathrm{K}}+\mathrm{IS}_{\mathrm{Cl}}\right) /\left(\mathrm{IS}_{\mathrm{Na}}+\mathrm{IS}_{\mathrm{K}}+\mathrm{IS}_{\mathrm{Cl}}\right)_{\mathrm{control}}$.

that corresponds to the specific electrical conductivity and the total $\mathrm{NaCl}$ (or $\mathrm{KCl}$ ) mEq. obtained by the process described above.

To check whether the DP data obtained are independent of the reference electrolyte used, Table 2 also shows the corresponding values obtained in the same way for $\mathrm{NaCl}$ and $\mathrm{KCl}$. The last two columns show the DP values obtained with $\mathrm{NaCl}$ and $\mathrm{KCl}$. It can be seen that these values are identical.

It can also be clearly observed in Table 2 that the HCTZ shows a $36 \%$ increase in DP, with respect to the control group, independently of the doses used, and the studied plants show an increase up to $21 \%$, in a dose-dependent manner in all the cases.

Finally, in Table 3, we compare the DP values with the other indexes: DI and ISi. It can be seen that the sequence variation of the three indexes is the same for HCTZ, WA and SC. In the case of AT, small discrepancies in the trend were observed that may be due to experimental errors.

\section{CONCLUSION}

The new and easy method for estimating the diuretic activity of drugs and plants we defined recently [14] is capable of accounting for the diuretic effect of a particular drug or plant with respect to a control value. Its application requires only two experimental parameters: the volume of urinary excretion and the specific electrical conductivity of the sample. The proposed method has been successfully applied in the study of three endemic diuretic plants of the
Canary Islands, affording results consistent with those previously reported, based on the diuretic and saliuretic indexes. Therefore, we believe that this new method is a suitable alternative for such studies.

\section{ACKNOWLEDGEMENT}

The authors thank the ORI (International Relations Office), University of La Laguna, for its collaboration, making the sojourn of D. B. possible.

\section{CONFLICT OF INTEREST STATEMENT}

The authors declare that there are no conflicts of interest.

\section{REFERENCES}

1. Lobo, V. M. M. 1989, Handbook of electrolyte solutions, Elsevier, New York.

2. Long, J. H. 1904, J. Am. Chem. Soc., 26, 93.

3. $\quad$ Long, J. H. 1902, J. Am. Chem. Soc., 24, 996.

4. Shedrovilzky, H., Nijensohn, C. M., Epszteyn, S., Falicov, R., Drajer, S., Neuman, J. and Berconsky, I. 1961, Rev. Asoc. Med. Argentina, 75, 10.

5. Hull, D. S. and Wolf, A. V. 1967, Proceed. Soc. Experiment. Biol. Med., 125, 936.

6. Wolf, A. V. and Pillay, V. K. G. 1969, Am. J. Med., 46, 837.

7. Kimura, T. and Yokoyama, R. 1973, Tohoku J. Exp. Med., 109, 281.

8. Jahrig, K., Bogun, K. R. and Grimmiger, J. 1977, Der Urologe Ausgabe A, 16, 204. 
9. Genain, C., Tellier, P., Syrota, A., Pocidalo, J. J. and Hanss, M. 1978, Clinica Chimica Acta, 88, 177.

10. Cunningham, J. J., Molnar, J. A., Meara, P. A. and Bode, H. H. 1986, Metab. Clin. Experiment., 35, 572.

11. Parkin, W. G. and Dickinson, R. W. 1987, Anaesth. Intens. Care, 15, 379.

12. Tiselius, H. G. 1992, J. Urol., 148, 990.

13. Kavukcu, S., Turkmen, M., Soylu, A. and Kuralay, F. 1998, J. Pak. Med. Assoc., 48, 238.
14. Hernández-Luis, F., Abdala, S., Dévora, S., Benjumea, D. and Martín-Herrera, D. 2014, J. Ethnopharm., 151, 1019.

15. Benjumea, D., Abdala, S., Hernández-Luis, F., Pérez-Paz, P. and Martín-Herrera, D. 2005, J. Ethnopharm., 100, 205.

16. Martín-Herrera, D., Abdala, S., Benjumea, D. and Pérez-Paz, P. 2007, J. Ethnopharm., 113, 487.

17. Abdala, S., Martín-Herrera, D., Benjumea, D. and Pérez-Paz, P. 2008, J. Ethnopharm., 119, 2. 